\title{
STRESS ANALYSIS OF PELTON BUCKET USING MECHANICAL APDL
}

\begin{tabular}{|l|l|l}
\hline Sonendra & N. Agarwal & T.S.Deshmuk \\
Mechanical Department, ITS & Mechanical Department, ITS & Civil Department. MANIT \\
Engineering College, Gr. & Engineering College, Gr. & Bhopal, Madhya Pradesh \\
Noida,Uttar Pradesh (India) & Noida,Uttar Pradesh (India) & (India) \\
sonendra.me@its.edu.in & namanaryan.agarwal@gmail.com & manit_tsd@yahoo.com
\end{tabular}

Abstract----In the present work an attempt has been made to analyse the stress developed on the surface of Pelton bucket using Mechanical APDL. The geometric modeling of this bucket has been done using CATIA software for a $50 \mathrm{~m}$ head and stress analysis has been done in Mechanical APDL. The stress analysis has been done considering bucket as a cantilever element fixed to the disc at one end with the force of jet applied at the splitter. The stress analysis has been done for flow rates ranging from $100 \mathrm{lit} / \mathrm{sec}$ to $150 \mathrm{lit} / \mathrm{sec}$ and speed ranging from $700 \mathrm{rpm}$ to $900 \mathrm{rpm}$. It is observed that $1^{\text {st }}$ principle stress is higher than $2^{\text {nd }}$ principle stress and $3^{\text {rd }}$ principle stress. Von Mises stress as well as all three principle stresses decreases as rotational speed of pelton wheel increases.

\section{I.INTRODUCTION}

The Pelton turbine is a hydraulic prime mover which generates power by first converting the pressure energy of water into kinetic energy with the help of jet nozzle assembly and then mechanical power is developed from this kinetic energy with the use of runner. Runner of Pelton turbine is made of buckets which are mounted on the periphery of a disc.The bucket of Pelton turbine has very complex geometry. The kinetic energy of a jet of water is converted into angular rotation of the bucket as the jet strikes. The high-velocity jet of water emerging from a nozzle impinges on the bucket and sets the wheel into motion.Pelton turbine is tangential flow impulse turbine.APelton turbine consists of a series of buckets mounted around the periphery of a circular disc.

\section{II.GEOMETRIC MODELLING}

The geometric modelling of the given pelton bucket has been done using CATIA software. In the present work, the runner of a Pelton turbine model for $50 \mathrm{~m}$ head has been used for stress analysis. The modelling of the runner blade surface was done with the help of profile coordinates at various sections.
The coordinates were available for 6 sections(A-A, BB, C-C, D-D, E-E, F-F) along the length of the blade and 5 sections (U-U, W-W, S-S, K-K, R-R) along the width of the blade. In addition to this, the coordinates of the plan view as well as lip surface were also available. Initially the curves for all the 11 sections were plotted (in different planes) with the distances between the adjacent sections being determined on the basis of plan view. Distance between splitter and E-E curve, E-E curve and A-A curve, A-A curve and F-F curve, F-F curve and B-B curve is $4.15 \mathrm{~mm}$. Distance between splitter and C-C curve is $28.07 \mathrm{~mm}$.

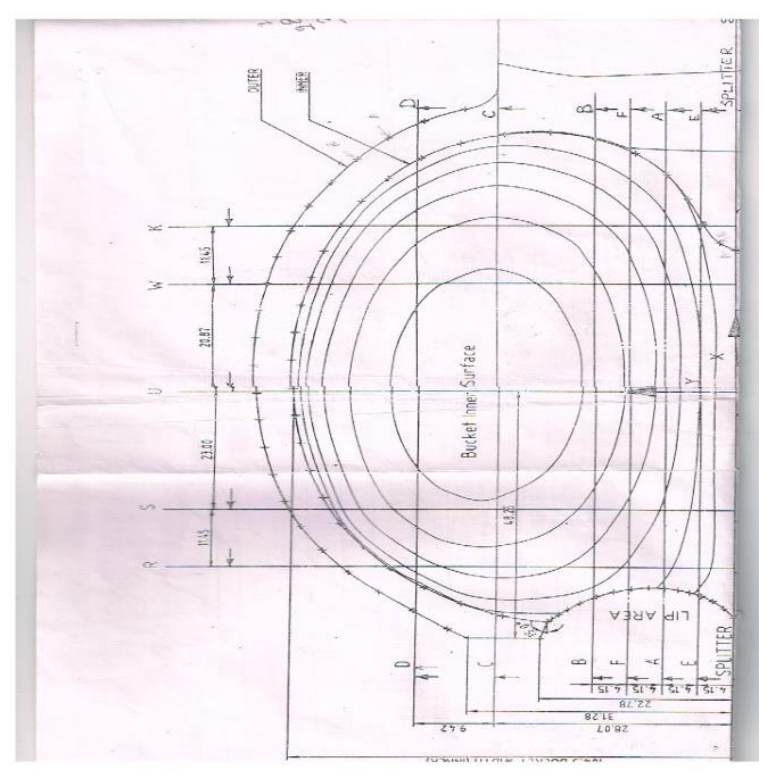

Fig.1 Profile of Pelton Bucket

Distance between splitter and DD curve is 37.49 mm.Section U-U passes through origin. Distance between U-U curve and W-W curve is $20.87 \mathrm{~mm}$. Distance between UU curve and SS curve is $23 \mathrm{~mm}$. Distance between $\mathrm{W}-\mathrm{W}$ and $\mathrm{K}-\mathrm{K}$ curve $11.45 \mathrm{~mm}$. 


\section{Asia Pacific Journals}

Distance between R-R and S-S curve is $11.45 \mathrm{~mm}$. The width of the bucket is $104.5 \mathrm{~mm}$. Using the given co-ordinates, curves were created using point and spline commands. The final assembly of all the bucket curves for 11 sections is shown below

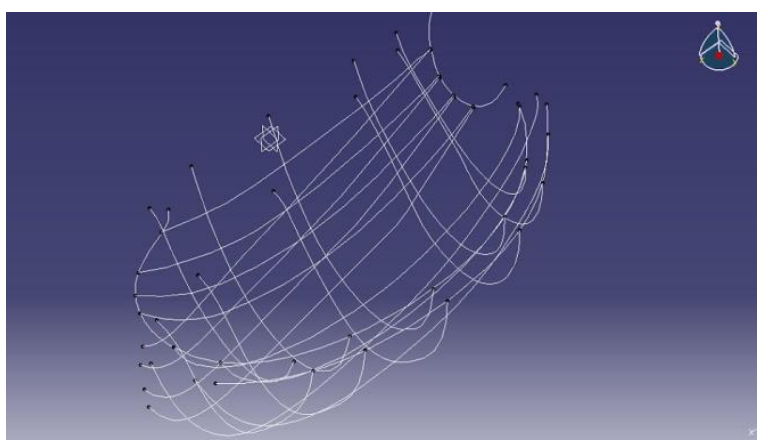

Fig.2 Sections of bucket profile

After this using inner curve of all sections (A-A, B-B, C-C, D-D, E-E, F-F, U-U,W-W, S-S, K-K, R-R ), a surface is generated. This surface forms the inner surface of bucket. Similarily using the outer curve of all sections the outer surface of bucket is created. Both surfaces are converted into a solid bath tub type shape. After this the lip area is created. In this way we obtained the profile of half-bucket. Mirror command is used to obtain remaining half profile of bucket. The complete solid model of the bucket is shown below

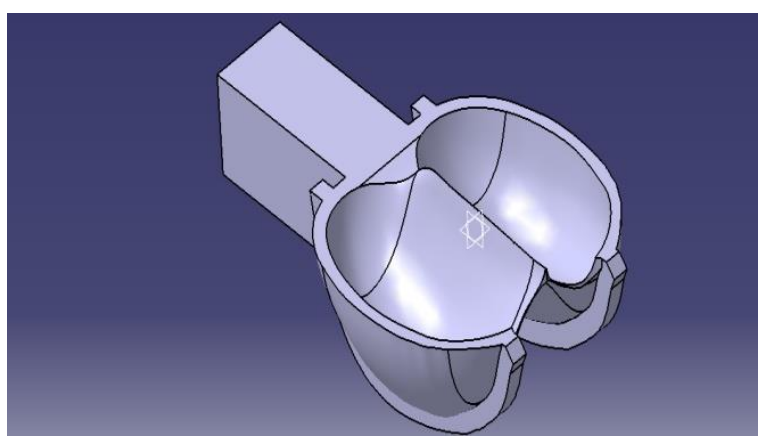

Fig.3. Solid Model of Pelton Bucket

\section{III.NUMERICAL SIMULATION}

numerical simulation of this problem is done using Mechanical APDL. This software is based on the principle of Finite Element Analysis. The basic steps involved in numerical analysis are as follows:

A. Pre-Processing-In the pre-processor the material definition and meshing of the imported solid model was done. The element used in this study is
SOLID187. After selecting the element type the material properties(Modulus of Elasticity, Poisson's Ratio, Tensile Strength, Ultimate)are defined. Meshing is very important part of pre-processing in any FEA software. Mechanical APDL offers two options - area, volume. Area is for 2D geometry and volume is for $3 \mathrm{D}$ geometry. In the present work volume was chosen. Free volume meshing is used for this analysis. Meshing done by this method is based on default setting.The obtained meshing of peltonbucket,had 38982 number of nodes.

B. Processing or Solution phase-In this phase, all the details for solution are specified. The analysis type used for stress calculations is static structure analysis.Load and constraints are considered as boundary conditions.

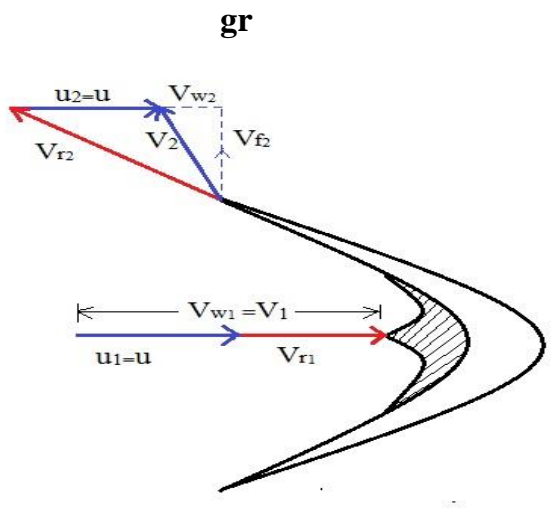

Fig.4 Velocity diagram of Pelton Bucket

In this present work, a force according to each operating condition (discharge and speed) is applied on the splitter and the constraint is in the form of fixed face of support of the bucket 


\section{Asia Pacific Journals}

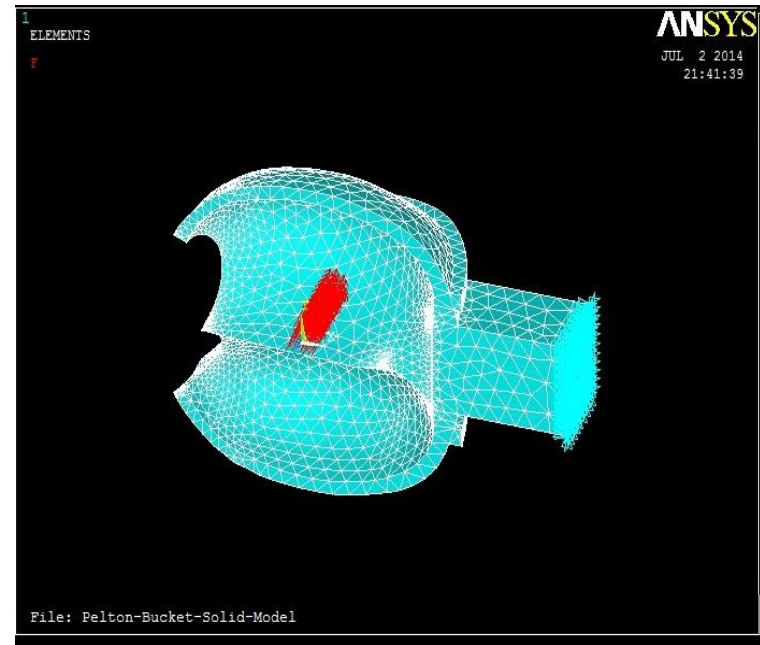

Fig.5 Boundary Conditions

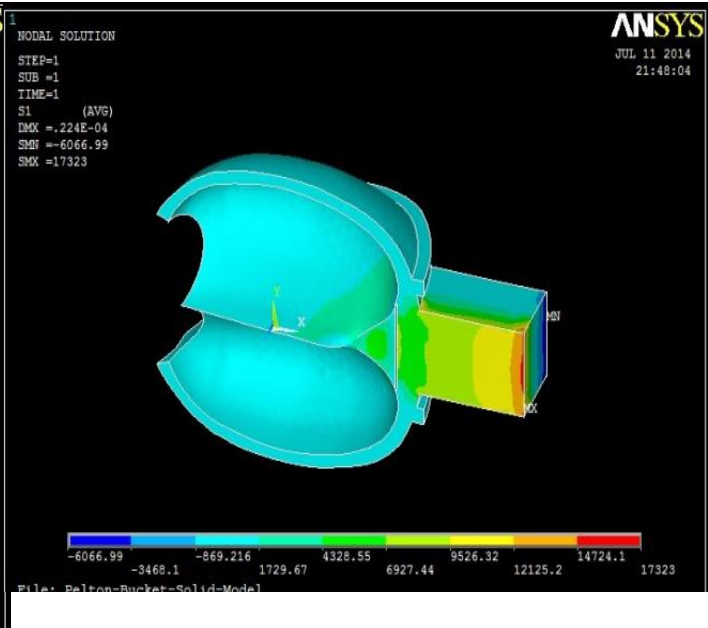

Fig.6 I $\mathrm{I}^{\text {st }}$ Principal Stress distribution for discharge $\mathrm{Q}=123$ lit/secand speed $\mathrm{N}=820 \mathrm{rpm}$

A Total number of 9 operating conditions have been considered for the analysis.

TABLE.I

Forces on Pelton Bucket at different flow rates

\begin{tabular}{|c|c|c|c|}
\hline Speed & $\begin{array}{c}700 \\
\mathrm{rpm}\end{array}$ & $\begin{array}{c}820 \\
\mathrm{rpm}\end{array}$ & $900 \mathrm{rpm}$ \\
\hline $100 \mathrm{lit} / \mathrm{sec}$ & $2947 \mathrm{~N}$ & $2491 \mathrm{~N}$ & $2185 \mathrm{~N}$ \\
\hline $123 \mathrm{lit} / \mathrm{sec}$ & $3624 \mathrm{~N}$ & $3064 \mathrm{~N}$ & $2687 \mathrm{~N}$ \\
\hline $150 \mathrm{lit} / \mathrm{sec}$ & $4420 \mathrm{~N}$ & $3736 \mathrm{~N}$ & $3277 \mathrm{~N}$ \\
\hline
\end{tabular}

Force on bucket is given by- $\mathrm{F}=\rho \mathrm{Q}\left(\mathrm{V}_{\mathrm{u} 1}-\mathrm{V}_{\mathrm{u} 2}\right)$

C.Post- Processing- results have been plotted in the form of contour plots of following:

- $\quad 1^{\text {st }}$ Principal Stress

- $\quad 2^{\text {nd }}$ Principal Stress

- $\quad 3^{\text {rd }}$ Principal Stress

- Von Mises Equivalent Stress.

\section{IV.RESULT}

The results of the simulation have been presented in the form of contour plots obtained through the APDL software for the three principle as well as Von Mises stress.

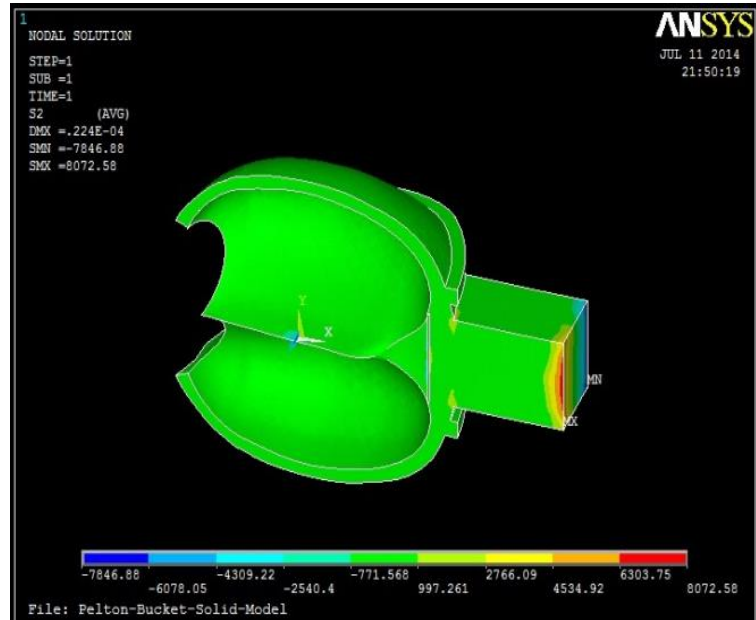

Fig.7 II ${ }^{\text {nd }}$ Principal Stress distribution for discharge $\mathrm{Q}=123 \mathrm{lit} / \mathrm{sec}$ and speed $\mathrm{N}=820 \mathrm{rpm}$ 


\section{Asia Pacific Journals}

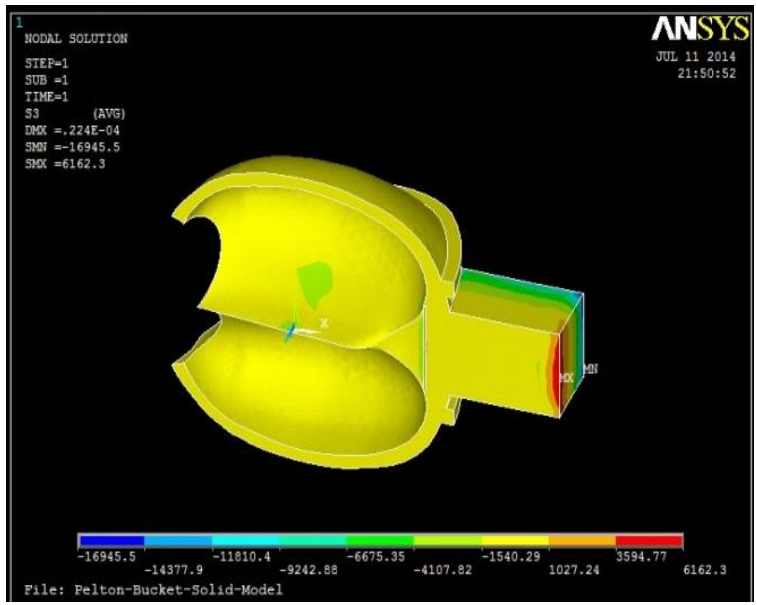

Fig.8 $3^{\text {rd }}$ Principal Stress distribution for discharge $Q=123$ lit/sec and speed $\mathrm{N}=820 \mathrm{rpm}$

A study of contour plots for principle stress with respect to blade surface (Fig 5.1) shows that the value of $1^{\text {st }}$ principle stress is more or less constant throughout the blade surface except for a triangular region near the joint of the blade surface and the support. Thereafter from the joint to the fixed edge of the support the stress increases steadily reaching a maximum value at the edge. This is probably because the jet of fluid returns back after reaching the end of blade surface hence creating large stresses at the joint of the jet and support.

$2^{\text {nd }}$ Principle stress (Fig 5.2) is constant throughout the blade surface as well as the support except at the fixed edge of the support where it shows higher stress. As the jet bifurcates at the splitter in two opposite direction hence the axial thrust gets nullified.

$3^{\text {rd }}$ Principle stress also shows (Fig 5.3) uniform stress all along the blade surface as well as the support except at the location where the jet strikes and at the

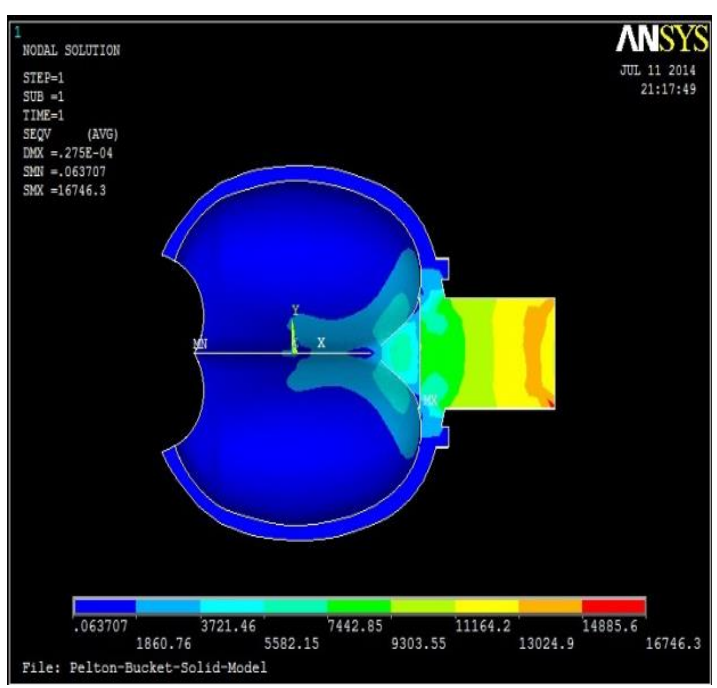

ELK Asia Pacific Journals - Special Issue ISBN: 978-81-930411-4-7

fixed edge of the support.

Fig 9 Von MisesStress distribution for discharge $Q=123$ lit/sec and speed $\mathrm{N}=700 \mathrm{rpm}$

. A study of contour plots of Von Mises stress show that in general the Von mises stresses are very low in the region between the lip section and the point of application of jet. The stress increases in a narrow zone from the point of application of jet. This zone of high stress widens gradually as we move towards the fixed end of blade and simultaneously the magnitude of stress also increases towards the fixed end. This zone of high stress inside the bucket is observed to follow the same pattern as that of the jet flow. Initially it is a narrow band which spreads out near the junction where the jet returns from the blade surface. Within this wide zone also the maximum stress is present in the centre which happens to be the location of the connection of the support. This increase in the stress is probably due to the turning of the jet which creates load on the blade surface.

When we consider the stress in the support then it is seen that the stress increases continuously from the connection with blade to the fixed end. This is obvious due to the cantilever action. Similarly if we consider the stress variation across the depth of the support then maximum stress are observed at the both bottom and top surfaces with minimum stress at the center region. This is also due to cantilever action.

It is observed that for a given discharge as the rotational speed is increase there is corresponding decrease in the magnitudes of all three principle stresses. The reduction of all three principle stresses and Von-mises stress with speed is shown in table below

Table II. Variation of Stress with speed

\begin{tabular}{|l|l|l|l|l|}
\hline \multirow{3}{*}{ Speed } & \multicolumn{4}{|c|}{ Discharge } \\
\cline { 2 - 5 } & $\begin{array}{l}\text { Stress } \\
\left(\mathbf{N} / \mathbf{m}^{2}\right)\end{array}$ & $\begin{array}{l}\mathbf{1 0 0} \\
\text { lit/sec }\end{array}$ & $\begin{array}{l}\mathbf{1 2 3} \\
\text { lit/sec }\end{array}$ & $\begin{array}{l}\mathbf{1 5 0} \\
\text { lit/sec }\end{array}$ \\
\hline $\begin{array}{l}900 \\
\text { rpm }\end{array}$ & $\begin{array}{l}\text { Von mises } \\
\text { Stress }\end{array}$ & 8685 & 9628 & 11339 \\
\cline { 2 - 5 } & $\begin{array}{l}1^{\text {st Principle }} \\
\text { Stress }\end{array}$ & 11022 & 12445 & 14408 \\
\cline { 2 - 5 } & $\begin{array}{l}2^{\text {nd }} \text { Principle } \\
\text { Stress }\end{array}$ & 5137 & 5798 & 6713 \\
\hline
\end{tabular}




\section{ELK}

Asia Pacific Journals

\begin{tabular}{|c|c|c|c|c|}
\hline & $\begin{array}{l}3^{\text {rd }} \text { Principle } \\
\text { Stress }\end{array}$ & 3928 & 4415 & 5118 \\
\hline \multirow{4}{*}{$\begin{array}{l}820 \\
\text { rpm }\end{array}$} & $\begin{array}{ll}\text { Von mises } \\
\text { Stress }\end{array}$ & 10578 & 13522 & 17091 \\
\hline & $\begin{array}{l}1^{\text {st }} \text { Principle } \\
\text { Stress }\end{array}$ & 13501 & 17323 & 21857 \\
\hline & $\begin{array}{l}2^{\text {nd }} \text { Principle } \\
\text { Stress }\end{array}$ & 6289 & 8072 & 10187 \\
\hline & $\begin{array}{l}3^{\text {rd }} \text { Principle } \\
\text { Stress }\end{array}$ & 4784 & 6162 & 7793 \\
\hline \multirow{4}{*}{$\begin{array}{l}700 \\
\text { rpm }\end{array}$} & $\begin{array}{ll}\text { Von mises } \\
\text { Stress }\end{array}$ & 14259 & 16746 & 22823 \\
\hline & $\begin{array}{l}1^{\text {st }} \text { Principle } \\
\text { Stress }\end{array}$ & 18361 & 21359 & 29137 \\
\hline & $\begin{array}{l}2^{\text {nd }} \text { Principle } \\
\text { Stress }\end{array}$ & 8556 & 9955 & 13580 \\
\hline & $\begin{array}{l}3^{\text {rd }} \text { Principle } \\
\text { Stress }\end{array}$ & 6527 & 7617 & 10386 \\
\hline
\end{tabular}

The principle stress vs speed graphs (fig 5.14 to 5.16) show that $1^{\text {st }}$ principle stress is higher than $2^{\text {nd }}$ and $3^{\text {rd }}$ principle stresses.

The reason behind this is already discussed while explaining the contour plots. It is observed that at higher speed (900 rpm), maximum stress is nearly same for all discharges. The value of this stress isabout $13000 \mathrm{~N} / \mathrm{m}^{2}$ for $1^{\text {st }}$ principle stress, $6000 \mathrm{~N} / \mathrm{m}^{2}$ for $2^{\text {nd }}$ principle stress and $4500 \mathrm{~N} / \mathrm{m}^{2}$ for $3^{\text {rd }}$ principle stress. At lower speed (700rpm), there is very less variation in stress for $100 \mathrm{lit} / \mathrm{sec}$ and $123 \mathrm{lit} / \mathrm{sec}$. This variation is about $14000 \mathrm{~N} / \mathrm{m}^{2}$ to $16000 \mathrm{~N} / \mathrm{m}^{2}$ for $1^{\text {st }}$ principle stress, $8500 \mathrm{~N} / \mathrm{m}^{2}$ to $10000 \mathrm{~N} / \mathrm{m}^{2}$ for $2^{\text {nd }}$ principle stress and $6500 \mathrm{~N} / \mathrm{m}^{2}$ to $7500 \mathrm{~N} / \mathrm{m}^{2}$ for $3^{\text {rd }}$ principle stress. The stress increases abruptly for 150 lit/sec. However in all cases the maximum principle stress is well below the yield limit of the material (650 $\mathrm{MPa})$.

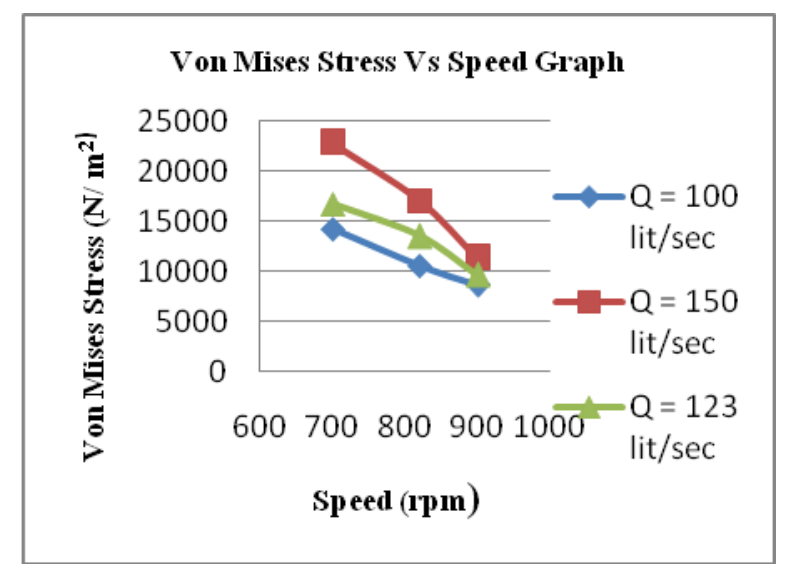

Fig 10. Variation of von mises stress with speed
ELK Asia Pacific Journals - Special Issue ISBN: 978-81-930411-4-7

it is also observed that for a given discharge as the rotational speed is increased, there is a corresponding decrease in the magnitude of the stress.

\section{V.CONCLUSION}

The reason for this decrease in stress with increase in rotational speed is probably due to the fact that as the speed increases the contact time of the jet on the blade decreases thus reducing the stress.

\section{REFERENCES}

[1] Argyris J.H. (1954). Recent Advances in Matrix Methods of Structural Analysis, Pergamon Press, Elmsgford, NY.

[2] Binaya K.C., BholaThapa, 2009, Pressure Distribution at Inner Surface of Selected Pelton Bucket For Micro Hydro,

[3] Clough R.W., September 8-9 1960, 'The Finite Element Method in Plane stresses Analysis" ,Proceeding of $2^{\text {nd }}$ ASCE Conference on Electronic computation, Pittsburg, P.A,.

[4] Hirt C.W., 1981, Nichols B.D, Volume of fluid method for dynamics of free boundaries, journal of computational physics

[5] I.U. Atthanayake, Department of Mechanical Engineering, October 2010, The Open University of Sri Lanka Nawala, Sri Lanka."Analytical Study On Flow Through a Pelton Turbine Bucket Using Boundary Layer Theory", International Journal of Engineering \& Technology IJET-IJENS Vol:09 No:09

[6] Mr. Patel Dhaval, Mr.GajeraChintan, Mr.ValaKuldip, 2010,"Stress \& Experimental Analysis Of Simple And Advanced Pelton Wheel.

[7] Nakanishi Y., Kubota and Shin T.,2002, "Numerical simulation of flows on pelton bucket by partial method: flow on a stationary rotating flat plate, " proceeding of 21th IAHR symposium, Lausanne, Sept. 9-12

[8] Roache, P.J. (1972). Computational Fluid Mechanics, Hermosa Publishers Albquerque, NM

[9] R. Angehrn, Safety Engineering for the 423 MW-PeltonRunners at Bieudron, August 6 - 9, 2000 VATech ESCHER WYSS, Zurich, Switzerland 